\title{
Fish consumption and CHD mortality: an updated meta-analysis of seventeen cohort studies
}

\author{
Jusheng Zheng ${ }^{1}$, Tao Huang ${ }^{1}$, Yinghua $\mathrm{Yu}^{1,2}{ }^{2}$, Xiaojie $\mathrm{Hu}^{1}$, Bin Yang ${ }^{1}$ and Duo $\mathrm{Li}^{1,3, *}$ \\ 'Department of Food Science and Nutrition, Zhejiang University, 268 Kaixuan Road, Hangzhou 310029 , \\ People's Republic of China: ${ }^{2}$ School of Health Sciences, University of Wollongong, Wollongong, New South \\ Wales, Australia: ${ }^{3}$ APCNS Centre of Nutrition and Food Safety, Hangzhou, People's Republic of China
}

Submitted 19 0ctober 2010: Accepted 29 July 2011: First published online 14 September 2011

\begin{abstract}
Objective: Results of studies on fish consumption and CHD mortality are inconsistent. The present updated meta-analysis was conducted to investigate the up-to-date pooling effects.

Design: A random-effects model was used to pool the risk estimates. Generalized least-squares regression and restricted cubic splines were used to assess the possible dose-response relationship. Subgroup analyses were conducted to examine the sources of heterogeneity.

Setting: PubMed and ISI Web of Science databases up to September 2010 were searched and secondary referencing qualified for inclusion in the study.

Subjects: Seventeen cohorts with 315812 participants and average follow-up period of $15 \cdot 9$ years were identified.

Results: Compared with the lowest fish intake ( $<1$ serving/month or 1-3 servings/ month), the pooled relative risk (RR) of fish intake on CHD mortality was 0.84 (95\% CI $0 \cdot 75,0 \cdot 95)$ for low fish intake (1 serving/week), $0 \cdot 79$ (95\% CI $0 \cdot 67,0 \cdot 92)$ for moderate fish intake (2-4 servings/week) and 0.83 (95\% CI $0.68,1.01)$ for high fish intake ( $>5$ servings/week). The dose-response analysis indicated that every $15 \mathrm{~g} / \mathrm{d}$ increment of fish intake decreased the risk of CHD mortality by $6 \%$ $(\mathrm{RR}=0.94 ; 95 \% \mathrm{CI} 0.90,0.98)$. The method of dietary assessment, gender and energy adjustment affected the results remarkably.

Conclusions: Our results indicate that either low (1 serving/week) or moderate fish consumption (2-4 servings/week) has a significantly beneficial effect on the prevention of CHD mortality. High fish consumption ( $>5$ servings/week) possesses only a marginally protective effect on CHD mortality, possibly due to the limited studies included in this group.
\end{abstract}

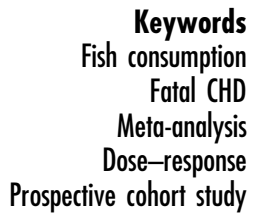

Over the past three decades there has been renewed interest in dietary intake of fish and fish oil, rich in marinederived long-chain n-3 PUFA, and intense interest has been sparked by epidemiological studies which suggest a favourable effect of fish on $\mathrm{CHD}^{(1)}$. Low mortality rate from CHD in epidemiological studies has been reported in populations with high intake of fish, such as Alaskan Natives ${ }^{(2)}$, Greenland Eskimos ${ }^{(3)}$ and Japanese residing in fishing villages ${ }^{(4)}$. However, not all prospective cohort studies have found an inverse association between fish consumption and fatal $\mathrm{CHD}^{(5-7)}$. In addition, clinical trials of fish or fish oil in patients with CHD did not corroborate early observational findings ${ }^{(8,9)}$.

In 2004 , two meta-analyses ${ }^{(10,11)}$, which pooled all available cohort data at that time, reported significant inverse associations between fish consumption and fatal CHD. A consistent result was achieved in a quantitative analysis regarding this issue in $2005^{(12)}$. However, stratified analyses in these meta-analyses were limited and could not help explain the heterogeneity. In addition, among several ${ }^{(7,13-20)}$ recently published cohort studies, $\operatorname{most}^{(7,13,15,17,18,20)}$ of them showed no statistically significant inverse association between fish intake and CHD mortality. Therefore, these results to date are still inconsistent and more detailed stratified analyses need to be done to find the potential heterogeneity. As a result, it is necessary to update the meta-analysis with relevant cohort studies in relation to fish consumption and CHD mortality.

The objective of the present study was to investigate the association between fish consumption and fatal CHD with published, up-to-date cohort studies. In addition, dose-response analysis was conducted to get trend estimation and subgroup analyses were conducted to examine sources of heterogeneity. 


\section{Methods}

\section{Selection of studies}

We conducted a literature search in PubMed and ISI Web of Science up to September 2010 for all relevant papers published. Key words included 'fishes', 'fish oils', 'seafood', 'omega-3' or 'fatty acids' in combination with 'coronary disease' or 'myocardial infarction' (as Medical Subject Headings or text words) for the PubMed search. For the ISI Web of Science search, terms used as topic search included 'fish', 'fish oil', 'seafood', 'omega-3 fatty acids', ' $n-3$ fatty acid' or 'polyunsaturated fatty acid' in combination with 'cardiovascular disease', 'fatal coronary heart disease', 'fatal myocardial infarction' or 'CHD'. Furthermore, references from the retrieved articles were reviewed to make sure that all the relevant bibliographies published were reviewed. Our search was confined to English-language journals only.

Two of the authors (J.Z. and T.H.) conducted the search independently. Discrepancies were resolved through group discussion. The following inclusion criteria were used in our meta-analysis: (i) studies were restricted to prospective cohort study design; (ii) risk estimates (relative risk (RR) or hazard ratio (HR)) with their corresponding 95\% confidence interval of CHD mortality rate for each category of fish consumption were provided; and (iii) if cohorts were duplicated in more than one study, the most recent and complete study (most detailed category classification) was included.

We excluded studies if: (i) cross-sectional, case-control or experimental designs were used; (ii) the outcome was not fatal CHD; (iii) there were only two fish intake categories; and (iv) the reference group was not the lowest fish intake category or the reference fish intake category was too high to be comparable with other studies.

\section{Data extraction}

We collected the following data from each publication: the first author's name, year of publication, country of origin, range or mean of participants' age, duration of follow-up, gender, sample size, number of events for each fish consumption category, person-years for each fish consumption category, adjusted covariates, methods of outcome assessment, methods of dietary assessment, categories of fish consumption and their corresponding RR or HR with their 95\% CI for CHD mortality. We extracted the greatest degree of adjusted risk estimates from each study.

\section{Statistical analysis}

We standardized and categorized the fish consumption into four groups based on the fish intake frequency: (i) high ( $>5$ servings/week); (ii) moderate (2-4 servings/ week); (iii) low (1 serving/week); and (iv) very low (comparison group; $<1$ serving/month or $1-3$ servings/ month). If a study contained categories of both $<1$ serving/month and 1-3 servings/month, we chose the previous category as the very low group. We assigned each RR from included studies into its corresponding group. If more than one fish intake category fell into the same group of our meta-analysis, we combined the RR with inverse variance weights and conducted a sensitivity analysis to examine the influence of these studies (two in low fish intake group, six in moderate fish intake group). For the present meta-analysis, RR were used as the common risk assessment measurement and HR were considered as RR directly. RR from each study was transformed to its natural logarithm and the $95 \%$ CI was used to calculate the corresponding standard error. Combined RR was used in a study if it presented RR with multiple outcomes or multiple exposures $^{(21,22)}$. The combined RR were weighted by the inverse of their variances.

All meta-analyses as well as the dose-response analysis were conducted using the STATA statistical software package version 11 (StataCorp LP, College Station, TX, USA). For dose-response analysis, we used the method described by Greenland and Longnecker ${ }^{(23)}$ and Orsini et $a l .{ }^{(24)}$ to get study-specific slopes and 95\% CI from the natural logarithms of the RR and CI across categories of fish intake (nine studies). Amount of fish consumption, RR, 95\% CI and distribution of cases and person-years/ non-cases in each included study should be extracted according to this method; the GLST command in STATA was used to estimate the dose-response association. If the distribution of cases and person-years/non-cases was not provided, slopes were estimated using variance-weighted least-squares regression (eight studies) and the VWLS command was used accordingly. The median or mean amount of fish consumption in each category was used for the dose-response analysis. The midpoint of upper and lower boundaries was considered as the dose of each category if the study reported only the range of fish consumption. If the highest category was open-ended, we regarded it as of the same amplitude as the preceding one. The lowest boundary was set to zero if the lowest category was open. If studies reported fish consumption using servings of fish per day, we transferred the fish amount to gram level according to the description of the study. If there was no portion size description, we deemed it to be $105 \mathrm{~g} /$ serving according to He et al. $^{(10)}$. To assess for potential curvilinear relation, restricted cubic splines (three knots) were used to flexibly model and graph the $\mathrm{RR}^{(25)}$, and the MKSPLINE command, which is used for linear and restricted cubic spline construction in STATA, was chosen.

To obtain a pooled RR and its 95\% CI, log RR were weighted by the inverses of their variances. A randomeffects model which takes into account both withinand between-study variability was used to combine the studies. We assessed statistical heterogeneity with the $Q$ and $I^{2}$ statistics $^{(26)}$. $I^{2}$ values of $25 \%, 50 \%$ and $75 \%$ correspond to cut-off points for low, moderate and high degrees of heterogeneity, respectively. 
If heterogeneity was presented, we conducted metaregression with study population (non-US $v$. US), method of dietary assessment (interview $v$. self-administered questionnaire) and energy adjustment (yes $v$. no) to explore the sources of heterogeneity. Stratified analyses regarding the study region, dietary assessment, gender, follow-up period, publication year and energy adjustment were also conducted to further examine potential heterogeneity sources. A sensitivity analysis in which one study at a time was excluded was done to evaluate the effect of an individual study on the result. Funnel plots was used to assess the publication bias and Egger's regression test to determine funnel plot asymmetry ${ }^{(27)}$. $P<0 \cdot 10$ was deemed to possess publication bias. To identify and correct for funnel plot asymmetry arising from publication bias, the trim and fill algorithm was used $^{(28)}$. RR of excluded studies with only two fish intake categories (yes $v$. no) or studies in which the reference group was not the lowest fish intake group (highest $v$. reference) were pooled to examine the impact of these excluded studies on the overall conclusions.

\section{Results}

\section{Search results and study characteristics}

Figure 1 presents the detailed selection process. We identified twenty-nine potential studies ${ }^{(5-7,13-22,29-44)}$. Seven studies ${ }^{(29,31-33,37,43,44)}$ were excluded because of their incomplete information on RR estimation or fish intake. Two studies ${ }^{(18,42)}$ were excluded because the reference group was not the lowest exposure group. Two studies ${ }^{(7,20)}$ were excluded because their reference fish intake categories were extremely high compared with other studies. One study ${ }^{(34)}$ possessing a greatly different CHD baseline risk compared with the risk for the general population was ruled out. Three studies ${ }^{(17,36,38)}$ containing only two categories of fish consumption were excluded. One study ${ }^{(5)}$ which contained populations from three different regions was regarded as three independent cohort studies. Two studies ${ }^{(14,36)}$ which provided the data of men and women separately were recognized as two different cohort studies respectively. Thus our meta-analysis included fourteen articles with seventeen independent cohort studies.

Table 1 shows part of the information extracted from the included studies, which contained 4472 cases among 315812 participants. The duration of follow-up ranged from 6 years reported by Ascherio et al. ${ }^{(35)}$ to 30 years reported by Daviglus et al. ${ }^{(39)}$. Our meta-analysis included seventeen cohorts (seven from the USA, two from Asia and eight from Europe). Overall, eight cohorts used a self-administered questionnaire, while nine cohorts used an interview. Seven cohorts in six studies ${ }^{(7,13-16,19)}$ (from 2004 to 2010) were published recently and so not included in previous meta-analyses ${ }^{(10,11)}$.

\section{Pooled effect estimates of fish consumption on fatal CHD}

Pooled RR of CHD mortality in connection with low fish consumption (1 serving/week; sixteen studies included) indicated that individuals consumed 1 serving/week had

$$
\begin{aligned}
& 2648 \text { potential references retrieved by search } \\
& 2619 \text { articles excluded based on titles/abstracts using general selection } \\
& \text { criteria: cross-sectional, case-control or experimental studies were excluded } \\
& \text { (or generally because papers were not related to fish intake and CHD) } \\
& 29 \text { potential relevant articles identified for more detailed assessment } \\
& \begin{array}{|l|l|}
15 \text { articles excluded: } \\
7 \text { excluded due to their incomplete information on RR estimation or they are } \\
\text { letters to the editors/conference abstracts } \\
3 \text { excluded due to two fish intake categories } \\
2 \text { excluded due to their comparison group not being the lowest exposure } \\
\text { group } \\
1 \text { excluded due to a greatly different CHD baseline risk compared to risk for } \\
\text { general population } \\
2 \text { excluded due to the extremely high comparison group }
\end{array}
\end{aligned}
$$

Fig. 1 Flowchart of the study selection process 


\begin{tabular}{|c|c|c|c|c|c|c|c|c|}
\hline Study source & $\begin{array}{l}\text { Duration of } \\
\text { follow-up (years) }\end{array}$ & $\frac{\text { Participants }}{n}$ & $\begin{array}{c}\text { Events } \\
n\end{array}$ & $\begin{array}{c}\text { Men } \\
\%\end{array}$ & Fish intake category & $\begin{array}{l}\text { Exposure } \\
\text { assessment }\end{array}$ & $\begin{array}{l}\text { Outcome } \\
\text { assessment }\end{array}$ & Adjusted variables \\
\hline $\begin{array}{l}\text { Kromhout et al. } \\
(1985)^{(30)} \text {, the } \\
\text { Netherlands }\end{array}$ & 20 & 852 & 78 & 100 & $\begin{array}{l}0 \mathrm{~g} / \mathrm{d}^{*} ; 1-14 \mathrm{~g} / \mathrm{d} ; 15-29 \mathrm{~g} / \mathrm{dt} ; \\
30-44 \mathrm{~g} / \mathrm{d} \neq ; \geq 45 \mathrm{~g} / \mathrm{d} \neq\end{array}$ & Interview & $\begin{array}{l}\text { ICD-8 (codes } \\
410-413)\end{array}$ & $\begin{array}{l}\text { Age, systolic blood pressure, serum total cholesterol, cigarette } \\
\text { smoking, subscapular skinfold thickness, physical activity, } \\
\text { energy intake, dietary cholesterol, prescribed diet and } \\
\text { occupation }\end{array}$ \\
\hline $\begin{array}{l}\text { Ascherio et al. }(1995)^{(35)} \\
\text { USA }\end{array}$ & 6 & 44895 & 264 & 100 & 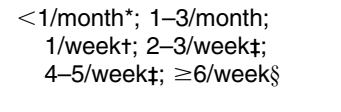 & $S A Q$ & $\mathrm{MR}, \mathrm{AR}$ & $\begin{array}{l}\text { Age, BMI, smoking habits alcohol consumption, history of } \\
\text { hypertension, history of diabetes, history of } \\
\text { hypercholesterolemia, family history of myocardial infarction } \\
\text { before } 60 \text { years of age and profession }\end{array}$ \\
\hline $\begin{array}{l}\text { Daviglus et al. }(1997)^{(39)} \\
\text { USA }\end{array}$ & 30 & 1822 & 430 & 100 & $\begin{array}{l}0 \mathrm{~g} / \mathrm{d}^{*} ; 1-17 \mathrm{~g} / \mathrm{d} ; 18-34 \mathrm{~g} / \mathrm{dt} ; \\
\quad \geq 35 \mathrm{~g} / \mathrm{d} \neq\end{array}$ & Interview & $\begin{array}{l}\text { ICD-8 (codes } \\
410-414)\end{array}$ & $\begin{array}{l}\text { Age, education, religion, systolic pressure, serum cholesterol, no. } \\
\text { of cigarettes smoked per day, BMI, diabetes, ECG } \\
\text { abnormalities, daily intakes of energy, cholesterol, SFA, MUFA, } \\
\text { PUFA, total protein, carbohydrate, alcohol, Fe, thiamin, } \\
\text { riboflavin, niacin, vitamin } C, \beta \text {-carotene and retinol }\end{array}$ \\
\hline Mann et al. $(1997)^{(6)}$, UK & $13 \cdot 3$ & 10802 & 64 & 38 & Never ${ }^{*} ;<1 /$ week $\geq 1 /$ weekt & SAQ & $\begin{array}{l}\text { ICD-9 (codes } \\
\quad 410-414)\end{array}$ & Age, sex, smoking and social class \\
\hline $\begin{array}{l}\text { Albert et al. }(1998)^{(40)} \text {, } \\
\text { USA }\end{array}$ & 11 & 20551 & 308 & 100 & 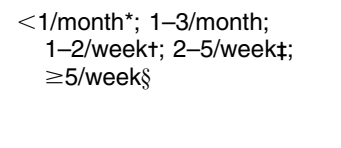 & SAQ & $\begin{array}{l}\text { ICD-9 (codes } \\
\quad 410-414)\end{array}$ & $\begin{array}{l}\text { Age, aspirin, } \beta \text {-carotene treatment assignment, evidence of CVD } \\
\text { before } 12 \text {-month questionnaire, BMI, smoking status, history of } \\
\text { diabetes, history of hypertension, history of } \\
\text { hypercholesterolaemia, alcohol consumption, vigorous } \\
\text { exercise, vitamin } E \text {, vitamin } C \text { and multivitamin use }\end{array}$ \\
\hline $\begin{array}{l}\text { Oomen et al. }(2000)^{(5)} \\
\text { Finland }\end{array}$ & 20 & 1088 & 242 & 100 & $\begin{array}{l}0-19 \mathrm{~g} / \mathrm{d}^{*} ; 20-39 \mathrm{~g} / \mathrm{dt} ; \\
\quad \geq 40 \mathrm{~g} / \mathrm{d} \neq\end{array}$ & Interview & $\begin{array}{l}\text { ICD-8 (codes } \\
\quad 410-414,795)\end{array}$ & $\begin{array}{l}\text { Age, BMl, cigarette smoking, intakes of energy, vegetables, fruit, } \\
\text { alcohol, meat, butter and margarine }\end{array}$ \\
\hline $\begin{array}{l}\text { Oomen et al. }(2000)^{(5)} \text {, } \\
\text { Italy }\end{array}$ & 20 & 1097 & 116 & 100 & $\begin{array}{l}0 \mathrm{~g} / \mathrm{d}^{*} ; 1-19 \mathrm{~g} / \mathrm{d} ; 20-39 \mathrm{~g} / \mathrm{dt} ; \\
\quad \geq 40 \mathrm{~g} / \mathrm{d} \neq\end{array}$ & Interview & $\begin{array}{l}\text { ICD-8 (codes } \\
410-414,795)\end{array}$ & $\begin{array}{l}\text { Age, BMI, cigarette smoking, intakes of energy, vegetables, fruit, } \\
\text { alcohol, meat, butter and margarine }\end{array}$ \\
\hline $\begin{array}{l}\text { Oomen et al. }(2000)^{(5)} \text {, } \\
\text { the Netherlands }\end{array}$ & 20 & 553 & 105 & 100 & $0 \mathrm{~g} / \mathrm{d}^{*} ; 1-19 \mathrm{~g} / \mathrm{d} ; \geq 20 \mathrm{~g} / \mathrm{d} \dagger$ & Interview & $\begin{array}{l}\text { ICD-8 (codes } \\
410-414,795)\end{array}$ & $\begin{array}{l}\text { Age, BMI, cigarette smoking, intakes of energy, vegetables, fruit, } \\
\text { alcohol, meat, butter and margarine }\end{array}$ \\
\hline $\begin{array}{l}\text { Yuan et al. (2001) } \\
\text { China }\end{array}$ & 12 & 18244 & 187 & 100 & $\begin{array}{l}<50 \mathrm{~g} / \mathrm{week}^{*} ; 50-<100 \mathrm{~g} / \\
\text { week; } 100-<150 \mathrm{~g} / \mathrm{weekt} ; \\
150-<200 \mathrm{~g} / \text { weekt; } \\
\geq 200 \mathrm{~g} / \text { week }\end{array}$ & Interview & $\begin{array}{l}\text { ICD-9 (codes } \\
410-414)\end{array}$ & $\begin{array}{l}\text { Age, total energy intake, level of education, BMI, current smoker, } \\
\text { average no. of cigarettes smoked per day, no. of alcoholic } \\
\text { drinks consumed per week, history of diabetes, history of } \\
\text { hypertension }\end{array}$ \\
\hline Hu et al. $(2002)^{(41)}$, USA & 16 & 84688 & 484 & 0 & 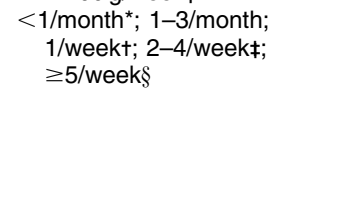 & SAQ & $\mathrm{MR}, \mathrm{DC}, \mathrm{AR}$ & $\begin{array}{l}\text { Age, time periods, smoking status, BMI, alcohol intake, } \\
\text { menopausal status and postmenopausal hormone use, } \\
\text { vigorous to moderate activity, no. of times aspirin was used per } \\
\text { week, multivitamin use, vitamin E supplement use, history of } \\
\text { hypertension, hypercholesterolaemia and diabetes, intake of } \\
\text { trans fat, ratio of polyunsaturated fat to saturated fat and dietary } \\
\text { fibre }\end{array}$ \\
\hline $\begin{array}{l}\text { Mozaffarian et al. } \\
(2003)^{(22)} \text {, USA }\end{array}$ & $9 \cdot 3$ & 3910 & 247 & 39 & 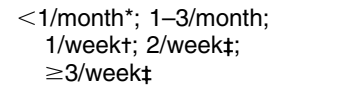 & $S A Q$ & MR, DC & $\begin{array}{l}\text { Age, gender, education, diabetes, smoking, BMI, systolic blood } \\
\text { pressure, LDL cholesterol, HDL cholesterol, TAG, C-reactive } \\
\text { protein, saturated fat, alcohol, beef/pork, fruit and vegetables }\end{array}$ \\
\hline $\begin{array}{l}\text { Folsom and Demissie } \\
\qquad(2004)^{(13)}, \text { USA }\end{array}$ & 14 & 41836 & 922 & 0 & $\begin{array}{l}<0.5 / \text { week }^{*} ; 0 \cdot 5-1 / \text { week; } \\
\text { 1.0-1.5/weekt; } \\
\text { 1.5-2.5/week‡; } \\
\quad \geq 2 \cdot 5 / \text { week }\end{array}$ & $S A Q$ & $\begin{array}{l}\text { ICD-9 (codes } \\
410-414,429 \cdot 2) \\
\text { or ICD-10 } \\
\text { (codes I20-125, } \\
\text { I51.6) }\end{array}$ & $\begin{array}{l}\text { Age, energy intake, educational level, physical activity level, } \\
\text { alcohol consumption, smoking status, pack-years of cigarette } \\
\text { smoking, age at first live birth, oestrogen use, vitamin use, BMI, } \\
\text { waist:hip ratio, diabetes, hypertension, intakes of whole grains, } \\
\text { fruit and vegetables, red meat, cholesterol and saturated fat }\end{array}$ \\
\hline $\begin{array}{l}\text { Järvinen et al. }(2006)^{(14)} \text {, } \\
\text { men, Finland }\end{array}$ & $21 \cdot 5$ & 2775 & 335 & 100 & $\begin{array}{l}\leq 11 \mathrm{~g} / \mathrm{d}^{*} ; 12-21 \mathrm{~g} / \mathrm{dt} ; \\
\quad 22-35 \mathrm{~g} / \mathrm{dt} ; 36-62 \mathrm{~g} / \mathrm{d} \neq \\
\quad \geq 63 \mathrm{~g} / \mathrm{d} \mathrm{g}\end{array}$ & Interview & $\begin{array}{l}\text { ICD-9 (codes } \\
410-414)\end{array}$ & $\begin{array}{l}\text { Age, energy intake, area, BMI, serum cholesterol, blood pressure, } \\
\text { smoking, occupation and diabetes }\end{array}$ \\
\hline $\begin{array}{l}\text { Järvinen et al. (2006) }{ }^{(14)} \text {, } \\
\text { women, Finland }\end{array}$ & $21 \cdot 5$ & 2445 & 163 & 0 & $\begin{array}{l}\leq 8 \mathrm{~g} / \mathrm{d}^{*} ; 9-15 \mathrm{~g} / \mathrm{d} ; 16-24 \mathrm{~g} / \mathrm{dt} ; \\
25-40 \mathrm{~g} / \mathrm{d} \neq ; \geq 41 \mathrm{~g} / \mathrm{d} \neq\end{array}$ & ; Interview & $\begin{array}{l}\text { ICD-9 (codes } \\
410-414)\end{array}$ & $\begin{array}{l}\text { Age, energy intake, area, BMI, serum cholesterol, blood pressure, } \\
\text { smoking, occupation and diabetes }\end{array}$ \\
\hline $\begin{array}{l}\text { Yamagishi et al. } \\
(2008)^{(15)} \text {, Japan }\end{array}$ & $12 \cdot 7$ & 57972 & 419 & 39 & $\begin{array}{l}0-27 \mathrm{~g} / \mathrm{d}^{*} ; 27-39 \mathrm{~g} / \mathrm{d \ddagger} ; \\
39-53 \mathrm{~g} / \mathrm{d} \neq ; 53-72 \mathrm{~g} / \mathrm{d} \neq \\
\text { 72-229 g/d }\end{array}$ & SAQ & $\begin{array}{l}\text { ICD } 10 \text { (codes } \\
\text { I20-I25) }\end{array}$ & $\begin{array}{l}\text { Age, gender, energy, history of hypertension and diabetes } \\
\text { mellitus, smoking status, alcohol consumption, BMI, mental } \\
\text { stress, walking, sports, education level, total energy, and dietary } \\
\text { intakes of cholesterol, saturated and } n-6 \text { polyunsaturated fatty } \\
\text { acids, vegetables and fruit }\end{array}$ \\
\hline
\end{tabular}


a significant lower RR of CHD mortality compared with those who consumed fish less than 1 serving/month or 1-3 servings/month $(\mathrm{RR}=0 \cdot 84 ; 95 \%$ CI $0 \cdot 75,0 \cdot 95$; Fig. 2); slight heterogeneity was observed among studies $\left(P=0 \cdot 225, I^{2}=20 \cdot 1 \%\right)$ and exclusion of studies in which more than one category fell into the low fish consumption group did not markedly change the result $(\mathrm{RR}=0 \cdot 83$; $95 \%$ CI $0.74,0.94)$. Moderate fish consumption (2-4 serving/week; thirteen studies included) had lower CHD mortality by $21 \%(\mathrm{RR}=0 \cdot 79 ; 95 \%$ CI $0 \cdot 67,0 \cdot 92$; Fig. 3) compared with the very low fish consumption; significant heterogeneity was found among studies $(P=0.006$, $\left.I^{2}=56.7 \%\right)$ and exclusion of studies in which more than one category fell into the moderate fish consumption group did not change the result significantly $(R R=0 \cdot 80$; $95 \%$ CI $0 \cdot 62,1 \cdot 03$ ). High fish consumption ( $>5$ serving/ week; five studies included) had a marginally protective effect on fatal CHD $(\mathrm{RR}=0 \cdot 83 ; 95 \% \mathrm{CI} 0 \cdot 68,1 \cdot 01 ;$ Fig. 4$)$; no heterogeneity was found $\left(P=0 \cdot 451, I^{2}=0\right)$.

For dose-response analysis, every $15 \mathrm{~g} / \mathrm{d}$ increase of fish intake led to a significant reduction by $6 \%(\mathrm{RR}=$ 0.94; $95 \%$ CI 0.90, 0.98) for fatal CHD (Fig. 5). However, restricted cubic splines (Fig. 6) found some evidence of a non-linear association $(P$ value for linearity $=0 \cdot 01)$.

\section{Stratified analyses and publication bias diagnostics}

Stratified analyses were conducted to examine the sources of heterogeneity for low and moderate fish consumption, as shown in Table 3. For low and moderate fish consumption, pooled RR of studies conducted in the USA were $0 \cdot 81(95 \% \mathrm{CI} 0 \cdot 70,0 \cdot 93)$ and $0 \cdot 80(95 \% \mathrm{CI} 0 \cdot 70,0 \cdot 93)$ and consistent with the overall RR, while the heterogeneity was greatly reduced for both. The method of dietary assessment also affected the results. For moderate fish consumption, studies conducted by in-person interview shared a stronger inverse association $(\mathrm{RR}=0 \cdot 71 ; 95 \% \mathrm{CI}$ $0.53,0 \cdot 96)$ compared with self-administered questionnaire $(\mathrm{RR}=0 \cdot 91 ; 95 \% \mathrm{CI} 0 \cdot 81,1 \cdot 02)$; however, the heterogeneity was greatly reduced for self-administered questionnaire $\left(I^{2}=23 \cdot 1 \%\right) \quad$ compared with in-person interview $\left(I^{2}=67 \cdot 6 \%\right)$. Pooled RR estimate of fatal CHD among females was more evident than that of males for low fish consumption but not for moderate fish consumption. Pooled RR estimate of fatal CHD of studies with no energy adjustment was more evident than that with energy adjustment for both fish consumption models. For moderate model, the heterogeneity was reduced to be 0 for studies with no energy adjustment.

Pooled results of meta-regression indicated that none of the items used was a major contributor to the identified heterogeneity. Sensitivity analysis showed no significant change by excluding any study. For the low fish consumption model, visualization of the funnel plot (Fig. 7) and Egger's test $(P=0 \cdot 265)$ indicated no publication bias. For the moderate fish consumption model, visualization 


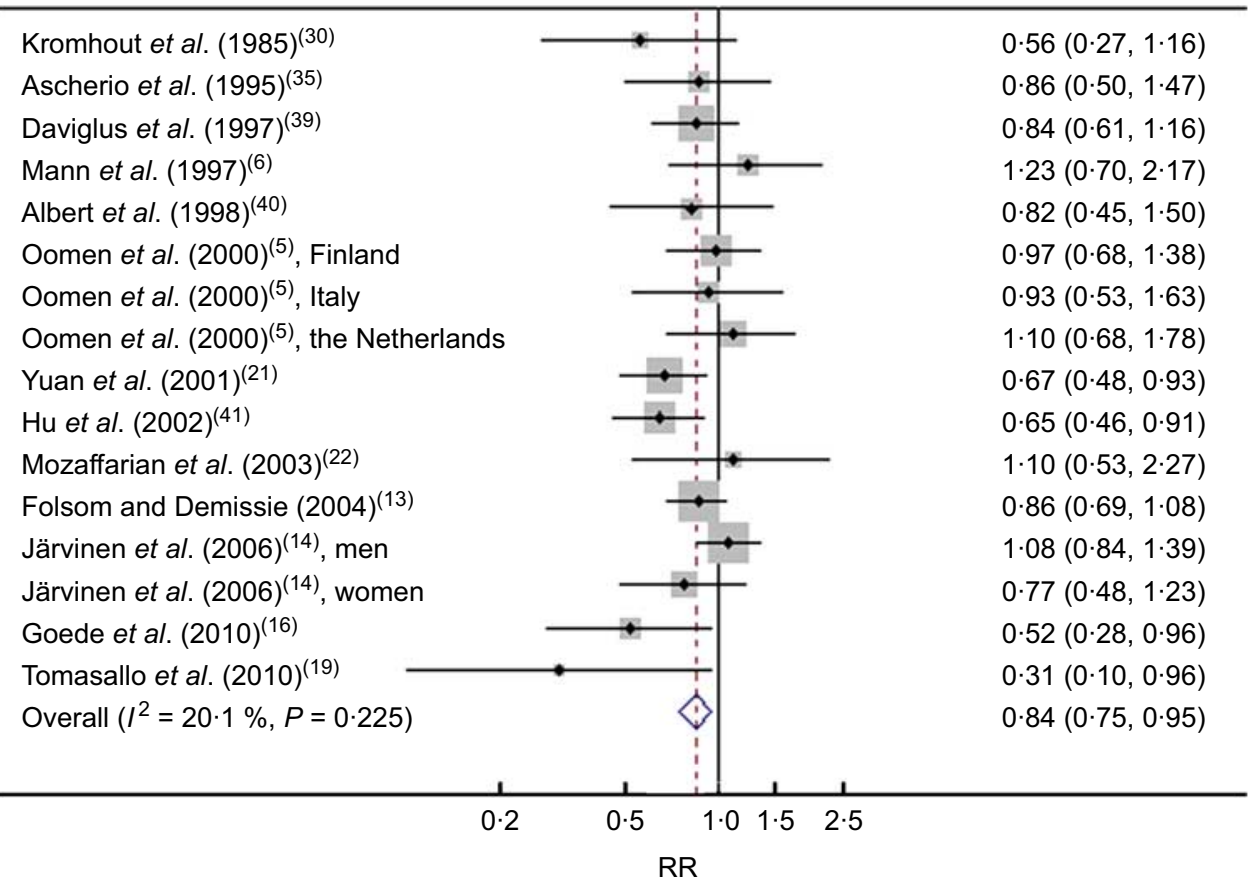

Fig. 2 (colour online) Pooled relative risk (RR) and $95 \% \mathrm{Cl}$ of studies assessing the association between low fish consumption (1 serving/week) and CHD mortality. Grey square represents the adjusted RR in each study, with the square size reflecting the study-specific weight and the $95 \% \mathrm{Cl}$ represented by horizontal bars. Open diamond indicates the pooled risk estimate and its corresponding $95 \% \mathrm{Cl}$

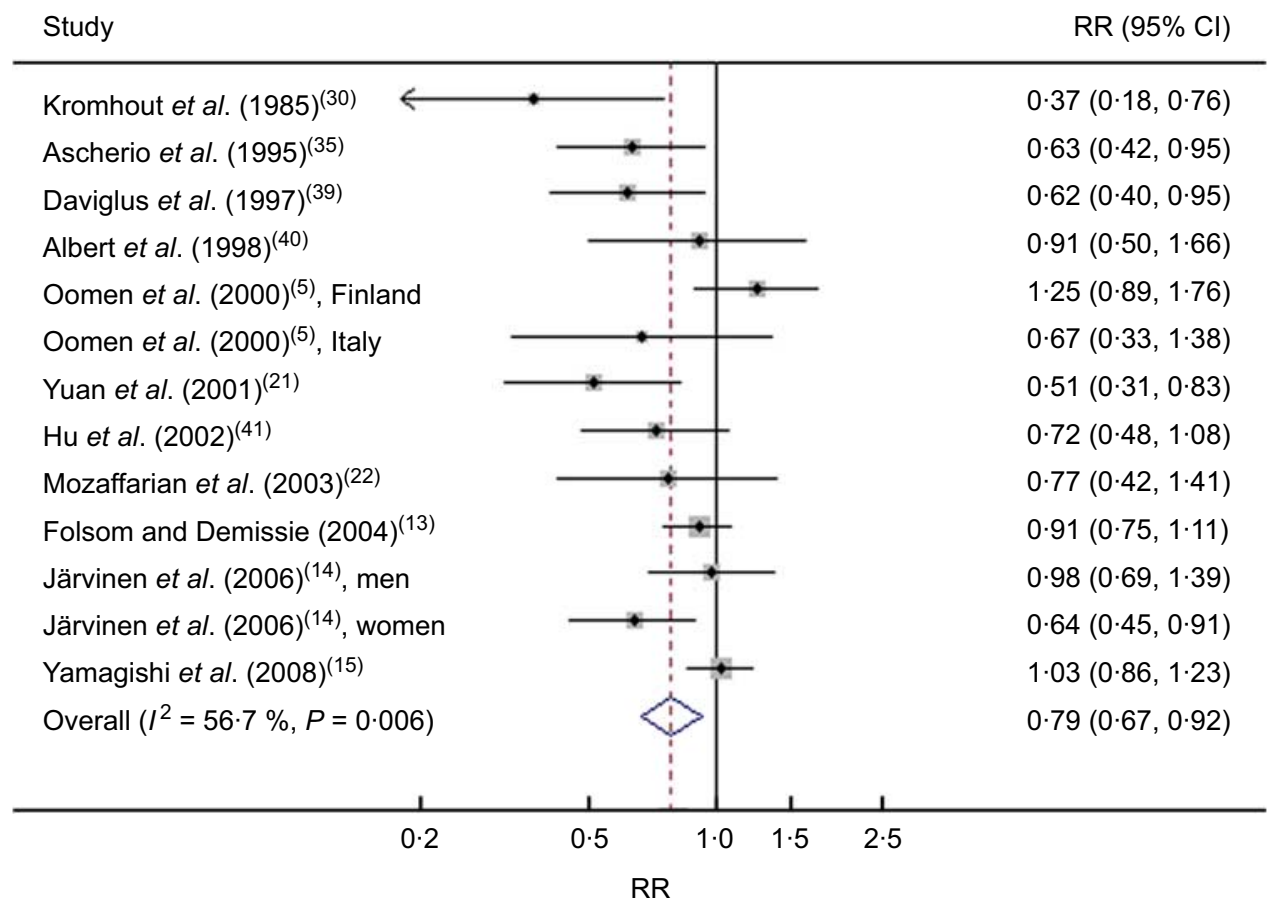

Fig. 3 (colour online) Pooled relative risk (RR) and $95 \% \mathrm{Cl}$ of studies assessing the association between moderate fish consumption (2-4 servings/week) and CHD mortality. Grey square represents the adjusted RR in each study, with the square size reflecting the study-specific weight and the $95 \% \mathrm{Cl}$ represented by horizontal bars. Open diamond indicates the pooled risk estimate and its corresponding $95 \% \mathrm{Cl}$ 


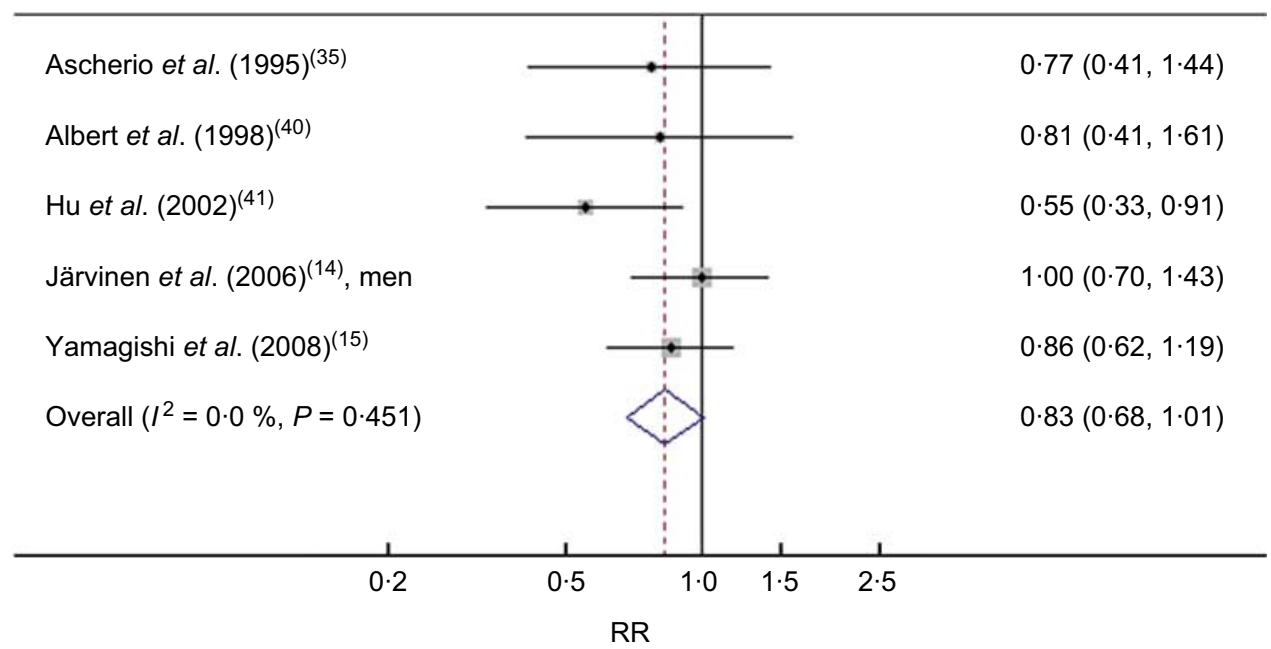

Fig. 4 (colour online) Pooled relative risk (RR) and $95 \% \mathrm{Cl}$ of studies assessing the association between high fish consumption (>5 servings/week) and CHD mortality. Grey square represents the adjusted RR in each study, with the square size reflecting the study-specific weight and the $95 \% \mathrm{Cl}$ represented by horizontal bars. Open diamond indicates the pooled risk estimate and its corresponding $95 \% \mathrm{Cl}$

Study

$\operatorname{RR}(95 \% \mathrm{Cl})$

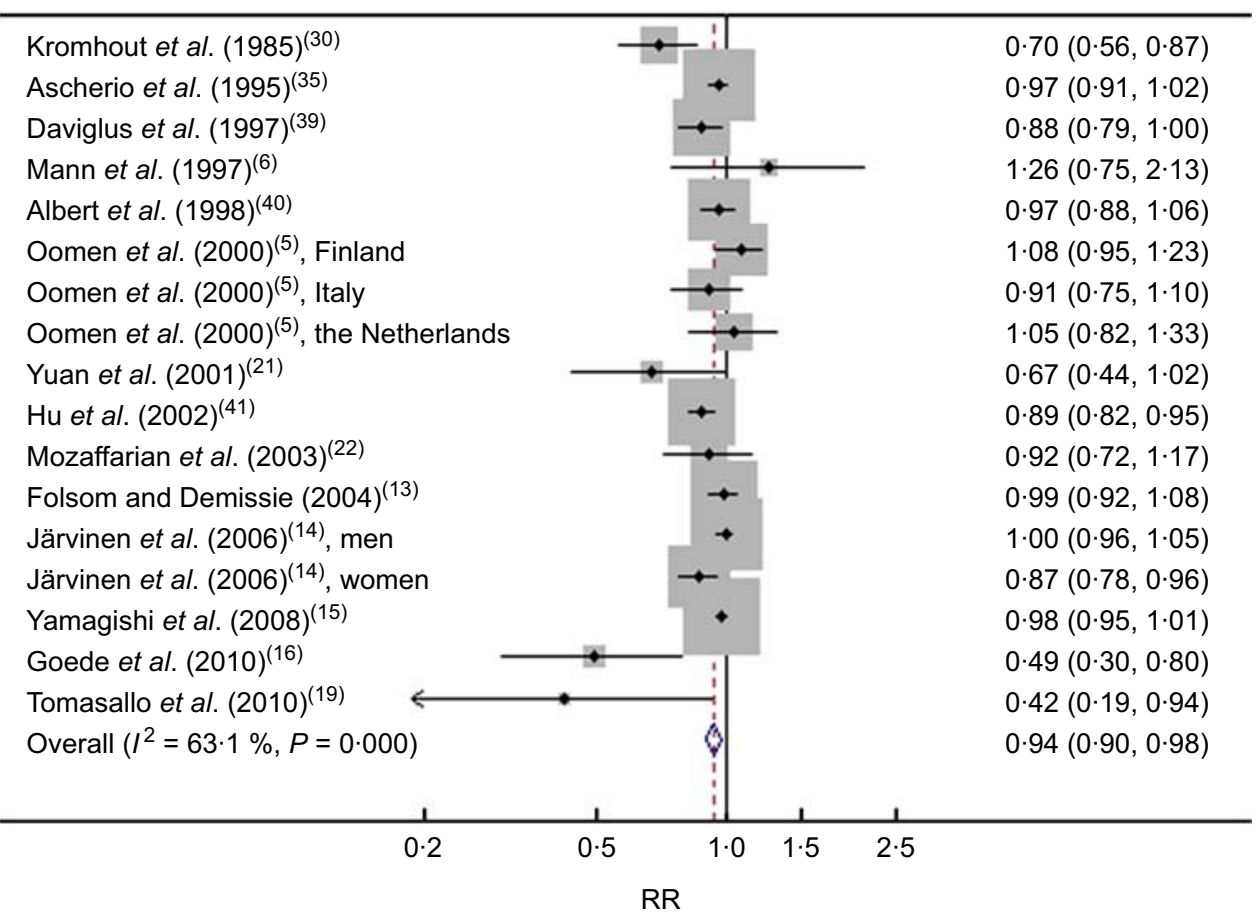

Fig. 5 (colour online) Pooled relative risk (RR) and $95 \% \mathrm{Cl}$ of studies assessing the association between an increment of $15 \mathrm{~g} / \mathrm{d}$ fish consumption and CHD mortality. Grey square represents the adjusted RR in each study, with the square size reflecting the study-specific weight and the $95 \% \mathrm{Cl}$ represented by horizontal bars. Open diamond indicates the pooled risk estimate and its corresponding $95 \% \mathrm{Cl}$

of the funnel plot (Fig. 8) and Egger's test $(P=0 \cdot 018)$ indicated publication bias and the pooled RR remained unchanged using the trim and fill method. The pooled RR of excluded studies with only two fish intake categories was $0.59(95 \%$ CI $0 \cdot 44,0 \cdot 80)$ and the significant inverse association still existed after adding another two excluded studies in which the reference was not the lowest fish intake category $(\mathrm{RR}=0 \cdot 69 ; 95 \%$ CI $0 \cdot 53,0 \cdot 91$; Fig. 9). 


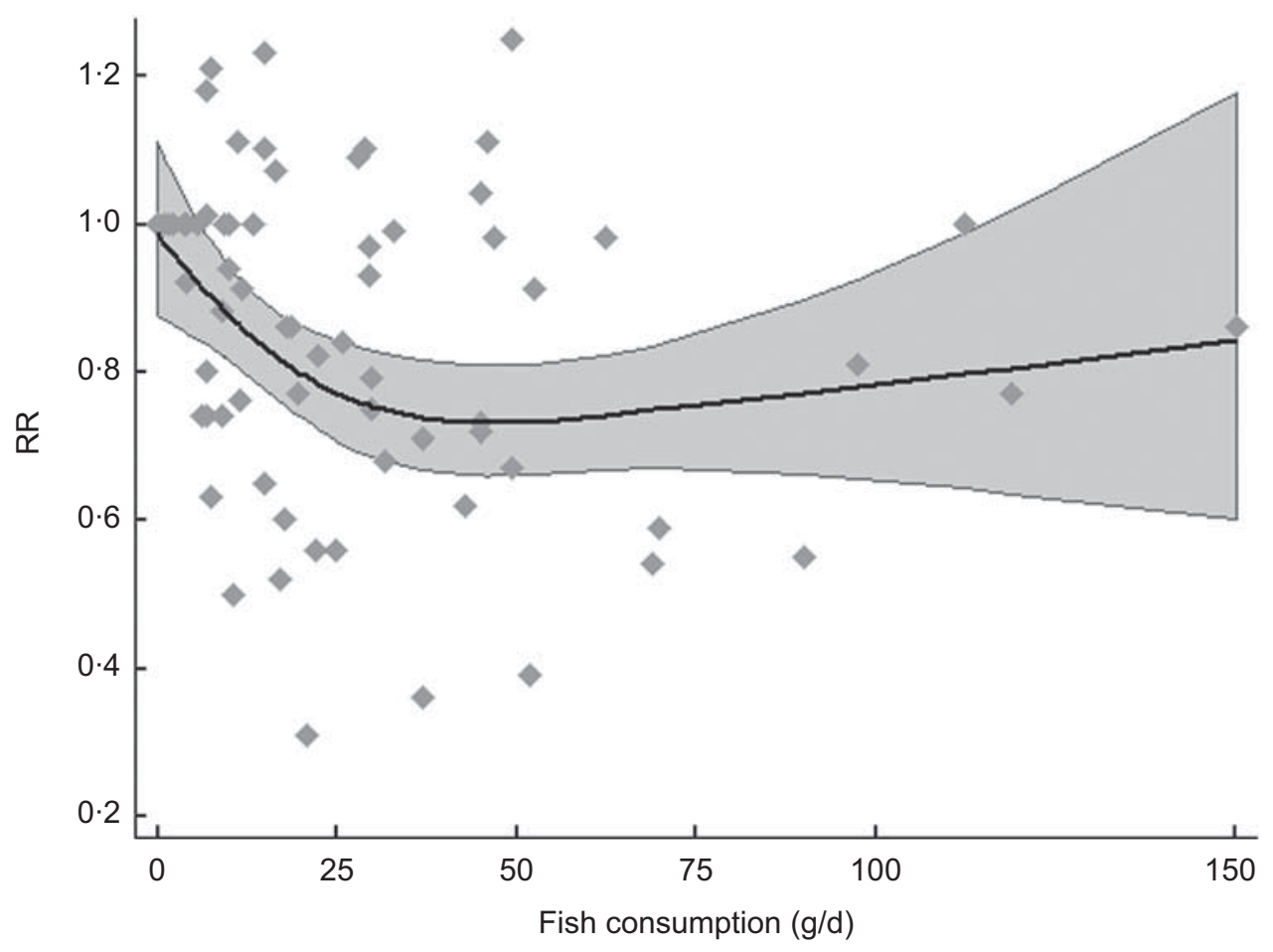

Fig. 6 Dose-response relationship between fish consumption $(\mathrm{g} / \mathrm{d})$ and $\mathrm{CHD}$ mortality with a restricted cubic spline model. The grey shaded area represents the $95 \%$ confidence limits for the fitted curve (RR, relative risk)

\section{Discussion}

The present study was an updated meta-analysis regarding fish consumption and CHD mortality. Its results showed a remarkable inverse association of moderate (2-4 servings/week) and low (1 serving/week) fish consumption with CHD mortality, adding updated information to the previous studies ${ }^{(10-12)}$. The protective effect of fish intake on CHD mortality was much stronger among those who shared the habit of moderate fish consumption (2-4 servings/week) than those who consumed low amounts of fish (1 serving/week). The protective effect of high fish consumption ( $>5$ servings/week) on fatal CHD was much weaker and this might be due to commonly existing contaminants such as methyl mercury in the fish counterbalancing the effect of protective components. Summary RR for different categories of fish exposure did not suggest an apparent linear dose-response relationship, and a possible J-shaped relationship between fish intake and CHD mortality was indicated with restricted cubic splines. Nevertheless there were only limited high fish consumption categories, and the analysis lacked statistical power to get a definite J-shaped relationship; in addition, a linear dose-response analysis showed that every $15 \mathrm{~g} / \mathrm{d}$ increment of fish consumption lowered CHD mortality by $6 \%$, which was consistent with previous results reported by $\mathrm{He}$ et al. ( $7 \%$ per $20 \mathrm{~g} / \mathrm{d}$ increment of fish intake) ${ }^{(10)}$ and Konig et al. $(5 \cdot 5 \%$ per $20 \mathrm{~g} / \mathrm{d}$ increment of fish intake) ${ }^{(12)}$.

\section{Stratified analyses}

For both low and moderate fish consumption models, inverse associations between fish consumption and CHD mortality in the USA were statistically significant compared with Europe where no significant inverse associations were observed; and there was no heterogeneity in the US studies. This might be partially due to the more detailed categorization among American studies that made corresponding fish intake categories more comparable with one another, thus decreasing the heterogeneity. Moreover, the differences between the cohorts may also have contributed to the results: different populations may respond differently to dietary fish rich in $n-3$ PUFA based on differing genetic backgrounds. Recent emerging data documenting genefatty acids interactions for CHD-related traits supported this hypothesis ${ }^{(45)}$. Besides population regions, the method of dietary assessment also affected the pooled RR; for moderate fish consumption, self-administered questionnaire rather than in-person interview reduced the heterogeneity significantly. This is contradictory to the common understanding that in-person interview may reduce the heterogeneity more evidently than self-administered questionnaire, and the reasons are yet to be investigated. Furthermore, for both fish consumption models, summary RR with no energy adjustment were more significant than with energy adjustment. The overall protective effect of fish on fatal CHD might be decreased if all the studies are adjusted for energy. In addition, for low fish consumption, no heterogeneity was observed for studies with 


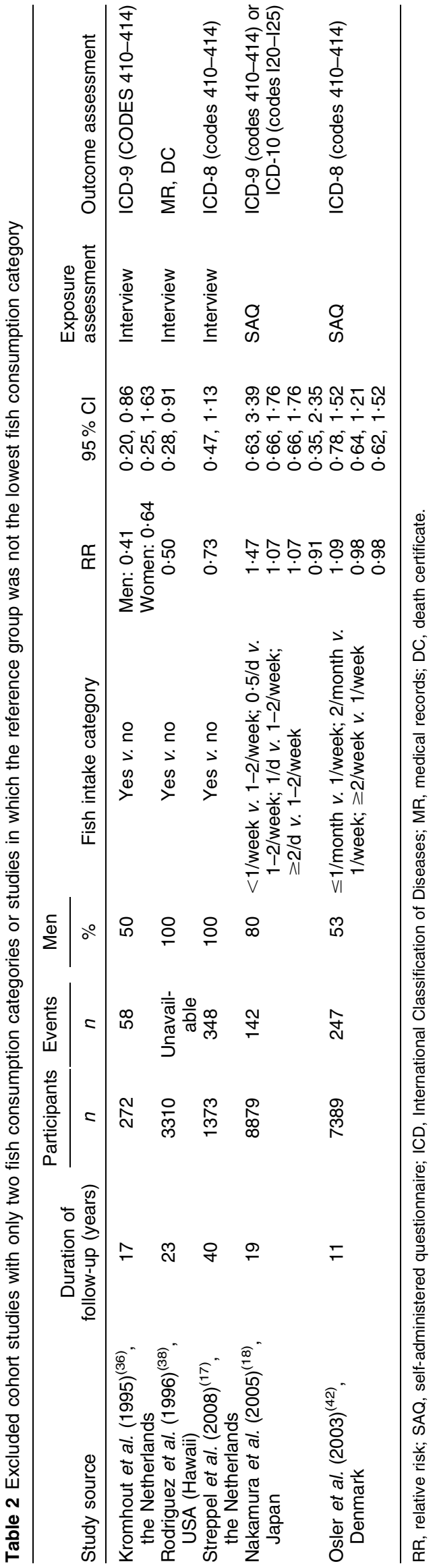

only male or female subjects. The more evident protective effect of fish on women might be partially due to the limited studies about women. More studies regarding women are needed to clarify the gender differences.

\section{Advantages and limitations}

The present meta-analysis possesses several advantages compared with previous ones. First, as category classification of fish consumption and portion size varied across studies, it was difficult to pool RR based on detailed fish intake between studies; however, our standardization generally unifies the fish consumption categories and gives a clear idea about the impact of fish intake on fatal CHD across different cohorts. Second, compared with the three previous studies ${ }^{(10-12)}$, the present study included more participants, providing updated information about the association between fish intake and CHD mortality. In addition, generalized least-squares regression was used to assess the possible dose-response relationship; this method provided more efficient estimation than weighted linear regression. Furthermore, a possible J-shaped relationship between fish consumption and fatal CHD was found with restricted cubic splines, which adds new information to the previous studies ${ }^{(10-12)}$; however, this relationship is weak due to the limited studies among high fish consumption groups and should be adopted cautiously.

In general, compared with previous meta-analyses, the present study adds more powerful statistical methods to achieve the dose-response analysis and more participants containing updated information on this topic. In addition, more detailed stratified analyses were conducted in our study to examine potential heterogeneity.

Some limitations of the present study should be mentioned. First, cohort studies could not avoid the residual confounding or bias, despite their relatively longer duration and larger sample size. Second, the high fish consumption group ( $>5$ servings/week) contained limited studies (five studies) owing to the fact that many studies possessed only limited fish intake categories, which could not be categorized into the high fish consumption group, and this might be a major limitation of the categorization in the meta-analysis. Third, six of the included studies did not adjust for energy; these studies showed more apparent protective effect, so the overall protective effect of fish on fatal CHD might be overestimated by the including these studies. Fourth, exclusion of studies with only two fish consumption categories or studies in which the reference group was not the lowest fish consumption category might bias our findings (Table 2), as the pooled RR of the excluded studies was more significant than either group of fish intake. Thus the inverse association of fish consumption and CHD mortality might be more significant if these studies could be categorized and included in the present meta-analysis. Fifth, if more than one fish intake category fell into the same group of our metaanalysis, we combined the RR with inverse variance 
Table 3 Stratified pooled risk estimates and $95 \%$ confidence intervals for low ( 1 serving/week) and moderate ( $2-4$ servings/week) fish consumption and CHD mortality

\begin{tabular}{|c|c|c|c|c|c|c|c|c|}
\hline \multirow[b]{2}{*}{ Subgroups } & \multicolumn{3}{|c|}{$\begin{array}{l}\text { Low fish consumption } \\
\text { (1 serving/week) }\end{array}$} & \multirow{2}{*}{$\begin{array}{l}\text { Heterogeneity } \\
\qquad I^{2}(\%)\end{array}$} & \multicolumn{3}{|c|}{$\begin{array}{l}\text { Moderate fish consumption } \\
(2-4 \text { servings/week) }\end{array}$} & \multirow{2}{*}{$\begin{array}{l}\text { Heterogeneity } \\
\qquad I^{2}(\%)\end{array}$} \\
\hline & $n$ & RR & $95 \% \mathrm{Cl}^{*}$ & & $n$ & RR & $95 \% \mathrm{Cl}^{*}$ & \\
\hline All studies & 16 & $0 \cdot 84$ & $0.75,0.95$ & $20 \cdot 1$ & 13 & 0.79 & $0.67,0.92$ & $56 \cdot 7$ \\
\hline \multicolumn{9}{|l|}{ Region } \\
\hline USA & 7 & $0 \cdot 81$ & $0 \cdot 70,0.93$ & 0 & 6 & $0 \cdot 80$ & $0 \cdot 70,0.93$ & 0 \\
\hline Europe & 8 & 0.95 & $0 \cdot 82,1 \cdot 11$ & $19 \cdot 7$ & 5 & 0.78 & $0.54,1 \cdot 12$ & $70 \cdot 7$ \\
\hline Finland & 3 & 0.99 & $0 \cdot 82,1 \cdot 20$ & 0 & 3 & 0.92 & $0.63,1.36$ & $73 \cdot 1$ \\
\hline Netherland & 3 & $0 \cdot 76$ & $0.54,1.06$ & $54 \cdot 6$ & 1 & $0 \cdot 37$ & $0 \cdot 18,0 \cdot 76$ & \\
\hline Asia & 1 & $0 \cdot 67$ & $0.48,0.93$ & & 2 & 0.75 & $0 \cdot 38,1 \cdot 49$ & $85 \cdot 8$ \\
\hline \multicolumn{9}{|l|}{ Follow-up period (years) } \\
\hline$\leq 10$ & 2 & 0.94 & $0.61,1.45$ & 0 & 2 & 0.67 & $0.48,0.94$ & 0 \\
\hline $10-20$ & 7 & $0 \cdot 74$ & $0.60,0.91$ & $35 \cdot 4$ & 5 & $0 \cdot 85$ & $0 \cdot 69,1 \cdot 04$ & $53 \cdot 2$ \\
\hline$\geq 20$ & 7 & $0 \cdot 94$ & $0 \cdot 82,1 \cdot 09$ & 0 & 6 & $0 \cdot 75$ & $0.55,1.03$ & $67 \cdot 6$ \\
\hline \multicolumn{9}{|l|}{ Dietary assessment } \\
\hline Interview & 9 & $0 \cdot 88$ & $0 \cdot 77,1 \cdot 00$ & $30 \cdot 6$ & 7 & $0 \cdot 71$ & $0.53,0.96$ & $67 \cdot 6$ \\
\hline Self-administered FFQ & 7 & $0 \cdot 82$ & $0 \cdot 70,0.95$ & $10 \cdot 7$ & 6 & $0 \cdot 91$ & $0.81,1.02$ & $23 \cdot 1$ \\
\hline \multicolumn{9}{|l|}{ Gender } \\
\hline Male & 9 & $0 \cdot 90$ & $0 \cdot 79,1 \cdot 02$ & 0 & 8 & $0 \cdot 73$ & $0.56,0.96$ & $62 \cdot 4$ \\
\hline Female & 3 & $0 \cdot 79$ & $0.66,0.94$ & 0 & 3 & $0 \cdot 82$ & $0 \cdot 70,0.96$ & $41 \cdot 8$ \\
\hline Both & 4 & $0 \cdot 75$ & $0 \cdot 42,1 \cdot 33$ & $60 \cdot 4$ & 2 & $1 \cdot 01$ & $0 \cdot 85,1 \cdot 20$ & 0 \\
\hline \multicolumn{9}{|l|}{ Published year } \\
\hline Before 2004 & 12 & $0 \cdot 83$ & $0.73,0.95$ & 0 & 9 & $0 \cdot 71$ & $0.56,0.90$ & $52 \cdot 1$ \\
\hline After 2004 & 5 & $0 \cdot 80$ & $0.61,1.05$ & $55 \cdot 6$ & 4 & 0.93 & $0 \cdot 83,1 \cdot 04$ & $48 \cdot 7$ \\
\hline \multicolumn{9}{|l|}{ Energy adjustment } \\
\hline Yes & 10 & $0 \cdot 87$ & $0.78,0.97$ & $18 \cdot 8$ & 9 & 0.80 & $0.65,0.98$ & 67 \\
\hline No & 6 & 0.79 & $0.63,0.99$ & $30 \cdot 1$ & 4 & 0.72 & $0.57,0.92$ & 0 \\
\hline
\end{tabular}

RR, relative risk.

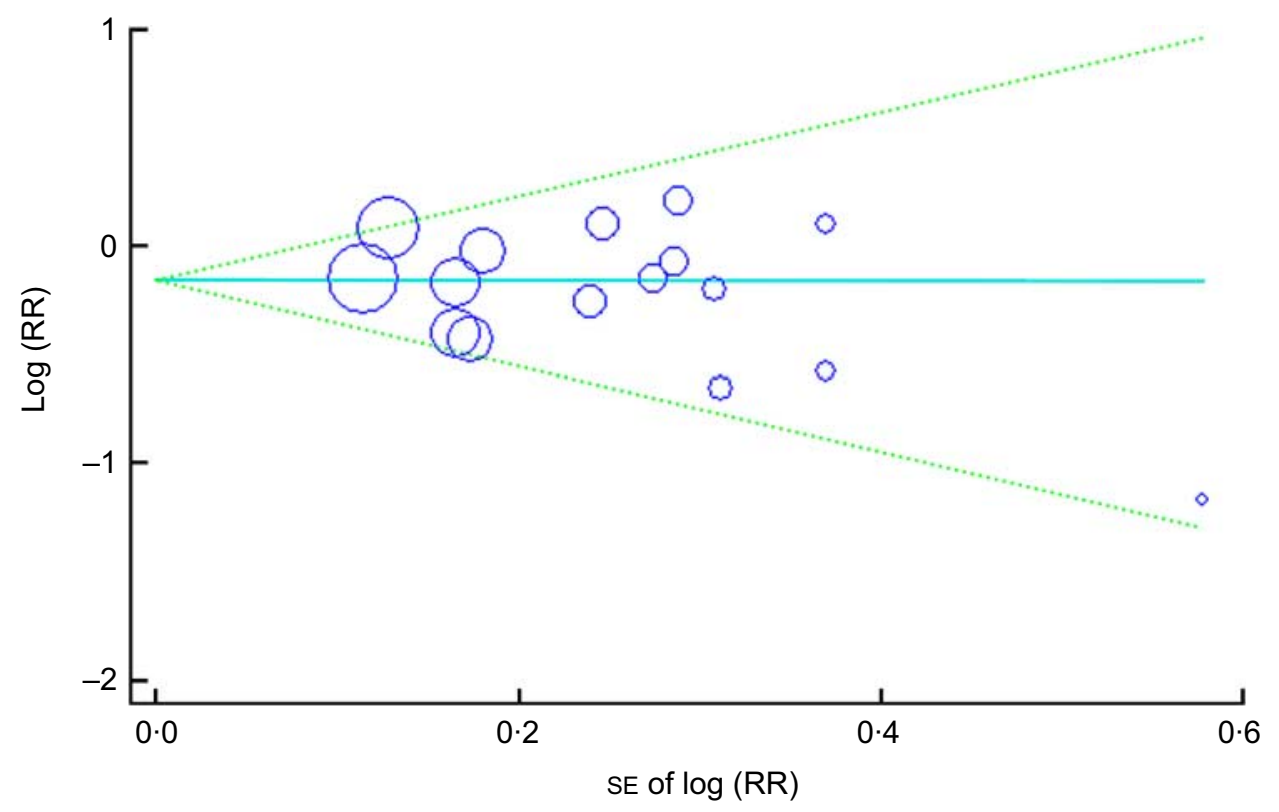

Fig. 7 (colour online) Begg's funnel plot with pseudo 95\% confidence limits indicating the publication bias of the relative risk (RR) assessing the association of low fish consumption (1 serving/week) and CHD mortality. The horizontal line indicates the summary estimate of RR, with the sloping dashed lines representing the expected $95 \% \mathrm{Cl}$ for a given SE

weight. This procedure might lead to overestimation of the precision of the RR estimates; however, for both low and moderate fish consumption groups, our sensitivity analyses did not show any significant changes excluding these studies. In addition, for moderate fish consumption (2-4 servings/week), publication bias (trim and fill method did not change the pooled RR) was found in the meta-analysis and great heterogeneity was also observed; these might be partially due to the relatively wide range of moderate fish consumption (2-4 servings/week). We included papers published only in the English language, which would be the source of our publication bias. 


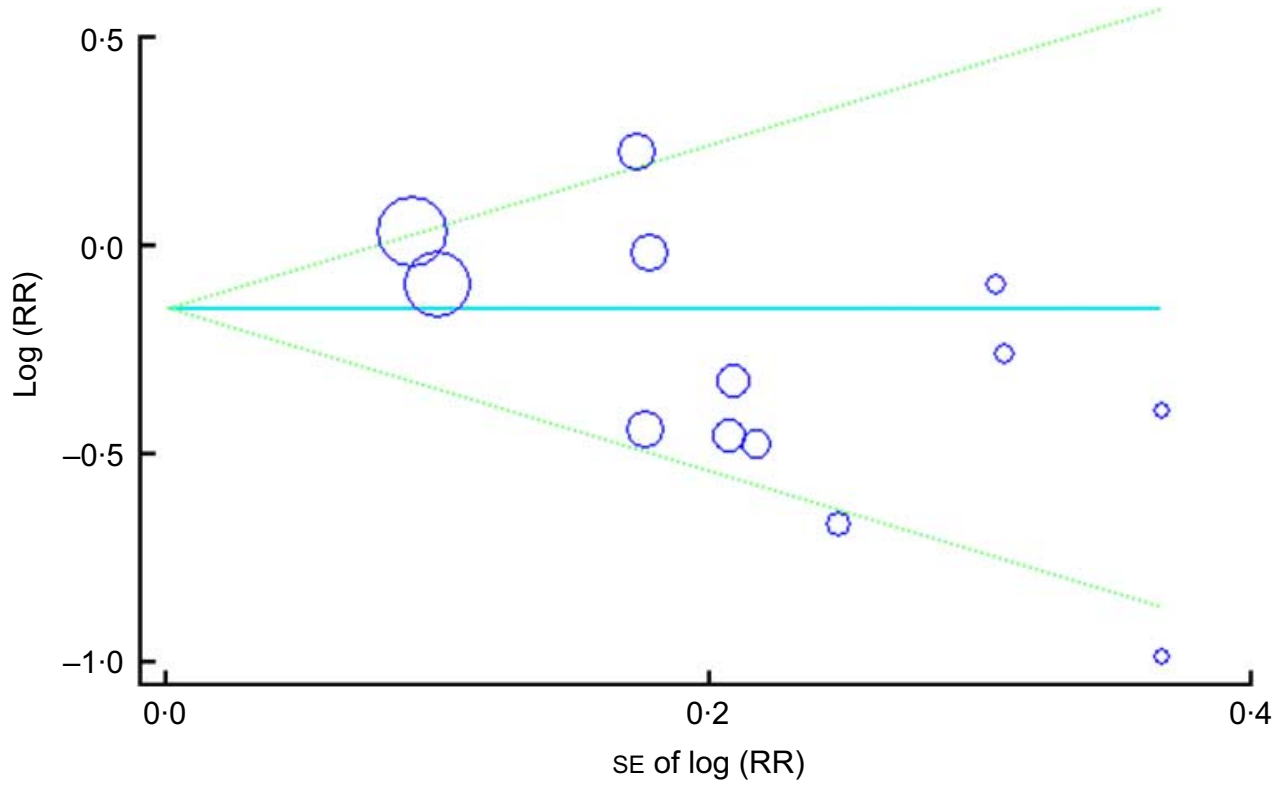

Fig. 8 (colour online) Begg's funnel plot with pseudo 95\% confidence limits indicating the publication bias of the relative risk (RR) assessing the association of moderate fish consumption (2-4 servings/week) and CHD mortality. The horizontal line indicates the summary estimate of RR, with the sloping dashed lines representing the expected $95 \% \mathrm{Cl}$ for a given SE

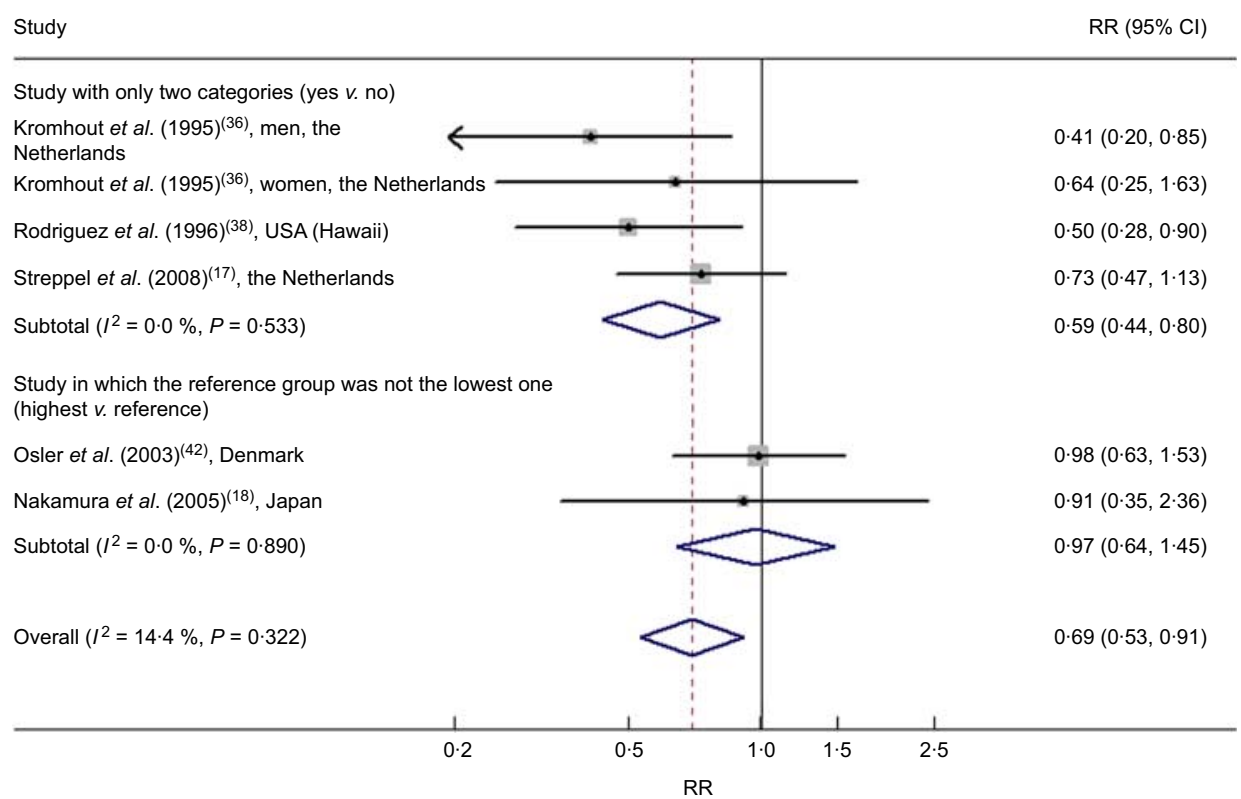

Fig. 9 (colour online) Pooled relative risk (RR) and $95 \% \mathrm{Cl}$ of excluded studies with only two fish intake categories (yes $v$. no) or studies in which the reference group was not the lowest fish intake category (highest $v$. reference) in assessing the association between fish consumption and CHD mortality. Grey square represents the adjusted RR in each study, with the square size reflecting the study-specific weight and the $95 \% \mathrm{Cl}$ represented by horizontal bars. Open diamond indicates the pooled risk estimate and its corresponding $95 \% \mathrm{Cl}$

Apart from the above issues, the cooking methods and contaminants (e.g. methyl mercury) of certain types of fish affect the results severely. However, among included studies, few ${ }^{(5,22)}$ contained information about these issues.

\section{Mechanisms of fish on fatal CHD}

It has long been assumed that long-chain $n-3$ PUFA, including $20: 5 n-3$ and $22: 6 n-3$, play an important role in the protective effect of fish on CHD risk. The possible mechanisms include their antiarrhythmic properties, reduction of serum TAG $^{(46)}$ and platelet aggregation ${ }^{(47)}$. Fish oil may also improve endothelial dysfunction ${ }^{(48)}$, which is considered an early marker of atherosclerosis. However, considering the synergic effect of many components in fish, such as high-quality protein, amino acid and vitamins, analysis of total fish consumption on CHD is probably 
more valuable than the sole evaluation of long-chain $n-3$ PUFA $^{(49)}$.

\section{Conclusion}

In conclusion, fish consumption of 1 serving/week or 2-4 servings/week has a significant protective effect on fatal CHD; fish consumption of $>5$ servings/week could marginally decrease CHD mortality, but the limited number of studies included in this group might contribute to the result. Our findings support the public dietary guideline to eat fish two times per week.

\section{Acknowledgements}

The project was funded by the National Natural Science Foundation of China (grant no. 30972464). There are no conflicts of interest. J.Z. and T.H. carried researched the studies for inclusion in the meta-analysis, extracted and analysed data, and drafted the manuscript; J.Z., T.H. and Y.Y. participated in manuscript preparation; and Y.Y., X.H., Y.B. and D.L. helped with revising the manuscript. The authors would thank Mr Ka He from the Departments of Nutrition and Epidemiology of the University of North Carolina at Chapel Hill for his suggestions and revisions of the draft manuscript.

\section{References}

1. Stone NJ (1996) Fish consumption, fish oil, lipids, and coronary heart disease. Circulation 94, 2337-2340.

2. Newman WP, Middaugh JP, Propst MT et al. (1993) Atherosclerosis in Alaska natives and non-natives. Lancet 341, 1056-1057.

3. Kromann N \& Green A (1980) Epidemiological studies in Upernavik District, Greenland. Acta Med Scand 208, 401-406.

4. Hirai A, Hamazaki T, Terano T et al. (1980) Eicosapentaenoic acid and platelet function in Japanese. Lancet 2, $1132-1133$.

5. Oomen CM, Feskens EJM, Rasanen L et al. (2000) Fish consumption and coronary heart disease mortality in Finland, Italy, and the Netherlands. Am J Epidemiol 151, 999-1006

6. Mann JI, Appleby PN, Key TJ et al. (1997) Dietary determinants of ischaemic heart disease in health conscious individuals. Heart 78, 450-455.

7. Iso H, Kobayashi M, Ishihara J et al. (2006) Intake of fish and $\mathrm{n} 3$ fatty acids and risk of coronary heart disease among Japanese: the Japan Public Health Center-Based (JPHC) Study Cohort I. Circulation 113, 195-202.

8. Yokoyama M, Origasa H, Matsuzaki M et al. (2007) Effects of eicosapentaenoic acid on major coronary events in hypercholesterolaemic patients (JELIS): a randomised openlabel, blinded endpoint analysis. Lancet 369, 1090-1098.

9. Burr ML, Ashfield-Watt PAL, Dunstan FDJ et al. (2003) Lack of benefit of dietary advice to men with angina: results of a controlled trial. Eur J Clin Nutr 57, 193-200.

10. He K, Song Y, Daviglus ML et al. (2004) Accumulated evidence on fish consumption and coronary heart disease mortality: a meta-analysis of cohort studies. Circulation 109, 2705-2711.

11. Whelton SP, He J, Whelton PK et al. (2004) Meta-analysis of observational studies on fish intake and coronary heart disease. Am J Cardiol 93, 1119-1123.

12. Konig A, Bouzan C, Cohen JT et al. (2005) A quantitative analysis of fish consumption and coronary heart disease mortality. Am J Prev Med 29, 335-346.

13. Folsom AR \& Demissie Z (2004) Fish intake, marine omega-3 fatty acids, and mortality in a cohort of postmenopausal women. Am J Epidemiol 160, 1005-1010.

14. Järvinen R, Knekt $\mathrm{P}$, Rissanen $\mathrm{H}$ et al. (2006) Intake of fish and long-chain $n-3$ fatty acids and the risk of coronary heart mortality in men and women. Br J Nutr 95, 824-829.

15. Yamagishi K, Iso H, Date C et al. (2008) Fish, omega-3 polyunsaturated fatty acids, and mortality from cardiovascular diseases in a nationwide community-based cohort of Japanese men and women the JACC (Japan Collaborative Cohort Study for Evaluation of Cancer Risk) Study. $J$ Am Coll Cardiol 52, 988-996.

16. de Goede J, Geleijnse JM, Boer JMA et al. (2010) Marine ( $n$-3) fatty acids, fish consumption, and the 10-year risk of fatal and nonfatal coronary heart disease in a large population of Dutch adults with low fish intake. J Nutr 140, 1023-1028.

17. Streppel MT, Ocke MC, Boshuizen HC et al. (2008) Longterm fish consumption and $n-3$ fatty acid intake in relation to (sudden) coronary heart disease death: the Zutphen study. Eur Heart J 29, 2024-2030.

18. Nakamura Y, Ueshima H, Okamura $\mathrm{T}$ et al. (2005) Association between fish consumption and all-cause and cause-specific mortality in Japan: NIPPON DATA80, 1980-99. Am J Med 118, 239-245.

19. Tomasallo C, Anderson H, Haughwout M et al. (2010) Mortality among frequent consumers of Great Lakes sport fish. Environ Res 110, 62-69.

20. Manger MS, Strand E, Ebbing M et al. (2010) Dietary intake of $n-3$ long-chain polyunsaturated fatty acids and coronary events in Norwegian patients with coronary artery disease. Am J Clin Nutr 92, 244-251.

21. Yuan JM, Ross RK, Gao YT et al. (2001) Fish and shellfish consumption in relation to death from myocardial infarction among men in Shanghai, China. Am J Epidemiol 154, 809-816.

22. Mozaffarian D, Lemaitre RN, Kuller LH et al. (2003) Cardiac benefits of fish consumption may depend on the type of fish meal consumed - The Cardiovascular Health Study. Circulation 107, 1372-1377.

23. Greenland S \& Longnecker MP (1992) Methods for trend estimation from summarized dose-response data, with application to meta-analysis. Am J Epidemiol 135, 1301-1309.

24. Orsini N, Bellocco R \& Greenland S (2006) Generalized least squares for trend estimation of summarized doseresponse data. Stata J 6, 40-57.

25. Harrell FE Jr, Lee KL \& Pollock BG (1988) Regression models in clinical studies: determining relationships between predictors and response. J Natl Cancer Inst 80, 1198-1202.

26. Higgins JP, Thompson SG, Deeks JJ et al. (2003) Measuring inconsistency in meta-analyses. BMJ 327, 557-560.

27. Egger M, Smith GD, Schneider M et al. (1997) Bias in metaanalysis detected by a simple, graphical test. BMJ 315, 629-634.

28. Duval S \& Tweedie R (2000) Trim and fill: a simple funnelplot-based method of testing and adjusting for publication bias in meta-analysis. Biometrics 56, 455-463.

29. Curb JD \& Reed DM (1985) Fish consumption and mortality from coronary heart-disease. $N$ Engl J Med 313, 821-822.

30. Kromhout D, Bosschieter EB \& Coulander CD (1985) The inverse relation between fish consumption and 20-year mortality from coronary heart-disease. $N$ Engl J Med 312, 1205-1209. 
31. Shekelle RB, Missell L, Paul O et al. (1985) Fish consumption and mortality from coronary heart-disease. $N$ Engl J Med 313, 820.

32. Vollset SE, Heuch I \& Bjelke E (1985) Fish consumption and mortality from coronary heart-disease. $N$ Engl J Med 313, 820-821.

33. Norell SE, Ahlbom A, Feychting M et al. (1986) Fish consumption and mortality from coronary heart-disease. BMJ 293, 426.

34. Fraser GE, Sabate J, Beeson WL et al. (1992) A possible protective effect of nut consumption on risk of coronary heart-disease - The Adventist Health Study. Arch Intern Med 152, 1416-1424.

35. Ascherio A, Rimm EB, Stampfer MJ et al. (1995) Dietaryintake of marine $n-3$ fatty-acids, fish intake, and the risk of coronary-disease among men. N Engl J Med 332, 977-982.

36. Kromhout D, Feskens EJM \& Bowles CH (1995) The protective effect of a small amount of fish on coronary heart-disease mortality in an elderly population. Int $J$ Epidemiol 24, 340-345.

37. Salonen JT, Nyyssonen K \& Salonen R (1995) Fish intake and the risk of coronary-disease. $N$ Engl J Med 333, 937.

38. Rodriguez BL, Sharp DS, Abbott RD et al. (1996) Fish intake may limit the increase in risk of coronary heart disease morbidity and mortality among heavy smokers - The Honolulu Heart Program. Circulation 94, 952-956.

39. Daviglus ML, Stamler J, Orencia AJ et al. (1997) Fish consumption and the 30-year risk of fatal myocardial infarction. N Engl J Med 336, 1046-1053.

40. Albert CM, Hennekens CH, O'Donnell CJ et al. (1998) Fish consumption and risk of sudden cardiac death. JAMA 279, $23-28$.
41. Hu FB, Bronner L, Willett WC et al. (2002) Fish and omega-3 fatty acid intake and risk of coronary heart disease in women. JAMA 287, 1815-1821.

42. Osler M, Andreasen AH \& Hoidrup S (2003) No inverse association between fish consumption and risk of death from all-causes, and incidence of coronary heart disease in middle-aged, Danish adults. J Clin Epidemiol 56, 274-279.

43. Meng LX, Wilkens L \& Kolonel L (2009) Fish consumption and ethnic differences in coronary heart disease mortality in a multiethnic cohort. Circulation 120, S498 (abstract 1404).

44. Zhang XH, Woo J \& Heller RF (2009) Increasing dietary fish intake has contributed to decreasing mortality from CHD among the older population in Hong Kong. Public Health Nutr 12, 1248-1253.

45. Tai ES, Corella D, Demissie S et al. (2005) Polyunsaturated fatty acids interact with the PPARA-L162 V polymorphism to affect plasma triglyceride and apolipoprotein C-III concentrations in the Framingham heart study. J Nutr $\mathbf{1 3 5}$, $397-403$.

46. Harris WS (1989) Fish oils and plasma lipid and lipoprotein metabolism in humans: a critical review. J Lipid Res 30, 785-807.

47. von Schacky C (2000) $n$-3 Fatty acids and the prevention of coronary atherosclerosis. Am J Clin Nutr 71, 1 Suppl., 224S-227S.

48. De Caterina R, Liao JK \& Libby P (2000) Fatty acid modulation of endothelial activation. Am J Clin Nutr $\mathbf{7 1}$, 1 Suppl., 213S-223S.

49. He K (2009) Fish, long-chain omega-3 polyunsaturated fatty acids and prevention of cardiovascular disease-eat fish or take fish oil supplement? Prog Cardiovasc Dis 52, 95-114. 